\title{
Ensifer (Sinorhizobium) fredii Interacted More Efficiently than Bradyrhizobium japonicum with Soybean
}

\author{
G. N. Pastorino', V. Martinez Alcántara' ${ }^{1}$, I. Malbrán ${ }^{2}$, L. Videira ${ }^{1}$, J. Sarinelli' \\ and P. A. Balatti $1^{1,2,3^{*}}$ \\ ${ }^{1}$ Chair of Agricultural Microbiology, National University of La Plata, Argentina. \\ ${ }^{2} \mathrm{CIDEFI}$ (Centre for Research in Plant Pathology), National University of La Plata, Argentina. \\ ${ }^{3}$ INFIVE (Institute of Plant Physiology), Faculty of Agricultural Sciences and Forestry, National \\ University of La Plata, Argentina.
}

\begin{abstract}
Authors' contributions
This work was carried out in collaboration between all authors. Author GNP designed and evaluated the competitive ability in co inoculated plants and made the statistical analysis. Author $L V$ works in the identification of organisms in the soil, designed and performed the study. Authors IM and JS design and performed the experiments aimed at analysing infection foci in inoculated plants and measured nodulation on a subset of these plants. Author VMA performed the evolution of nodulation efficiency by inoculating different cell concentrations. Author PAB collaborated in the design of the experiments, the statistical analysis of the results and wrote the paper. All authors read and approved the final manuscript.
\end{abstract}

Article Information

DOI: $10.9734 / J A E R I / 2015 / 13163$ Editor(s):

(1) Mirza Hasanuzzaman, Department of Agronomy, Faculty of Agriculture, Sher-e-Bangla Agricultural University, Dhaka-1207,

Bangladesh.

Reviewers:

(1) Anonymous, China Agricultural University, China. (2) Niokhor Bakhoum, Laboratoire Commun de Microbiologie IRD/ISRA/UCAD Dakar, Senegal. Complete Peer review History: http://www.sciencedomain.org/review-history.php?iid=682\&id=37\&aid=6346

Original Research Article

Received $6^{\text {th }}$ August 2014

Accepted $9^{\text {th }}$ September 2014

Published $6^{\text {th }}$ October 2014

\section{ABSTRACT}

Aims: The purpose of this work was to compare the efficiency of Bradyrhizobium japonicum and Ensifer fredii to infect and develop nodules on soybean. Furthermore we also evaluated the competitive ability of both species and how this was altered by the plant genotype and the soil pH. Study Design: The design of the experiments was completely at random and the number of replicates was different on each of the different experiments tested. 
Place and Duration of Study: The place of the studies was the Facultad de Ciencias Agrarias y Forestales Universidad Nacional de La Plata and the duration of the study was a year and a half.

Methodology: Roots of inoculated soybean plants were fixed and the number of infection initiation sites was evaluated by means of microscopic observation. The number of nodules developed by inoculated plants was also evaluated.

Results: Bacteria were equally effective at developing infection initiation sites on soybean however, $E$. fredii induced more nodules than $B$. japonicum, probably due to the fact that $E$. fredii is more efficient than B. japonicum at nodulating soybean. However, Bradyrhizobium was more competitive than $E$. fredii which was unrelated to the soybean genotype but altered by the soil $\mathrm{pH}$. Under the conditions described $E$. fredii was less competitive than $B$. japonicum probably due to the high cultivar-rhizobia specificity.

Conclusion: $E$. fredii was as efficient as $B$. japonicum at nodulating soybeans. However Bradyrhizobium was a better competitor though this is affected by the plant genotype and the soil $\mathrm{pH}$. The selection and use of fast growing rhizobia in inoculant production seems to depend on broadening the genetic base of soybean or in selecting cultivars with specificity for fast growing rhizobia.

Keywords: Bradyrhizobium; Ensifer fredii; nodulation; competition.

\section{INTRODUCTION}

Legumes constitute the third most important family of angiosperms (Fabaceae) $[1,2]$ and most of them establish a symbiotic association with Gram (-) bacteria commonly known as rhizobia [3].

Soybean (Glycine max (L.) Merr.) is the most important legume worldwide and nodulates with soil bacteria from the genus Bradyrhizobium, Mesorhizobium, Ensifer (Sinorhizobium) and Rhizobium [4,5,6,7,8]. Bradyrhizobium species that nodulate soybean include B. japonicum [9], $B$. elkanii [10], $B$. liaonengense [11] and $B$. daqingense [12]. In addition to this, soybean is also nodulated by fast growing rhizobia $[13,14]$ that include Ensifer (Sinorhizobium) fredii, E. (S.) xinjiangense and other unclassified rhizobia as well $[15,16,17]$. Additionally, Hungría et al. [18] and Appunu [19] found that also Mesorhizobium tianshanense and Rhizobium tropici nodulate soybean.

While B. japonicum and B. elkanii nodulate and fix nitrogen efficiently in association with improved soybean cultivars [10], fast growing rhizobia have been reported to interact inefficiently with soybean though several reports argue about this $[20,21,22,23]$. Unlike Bradyrhizobium siblings, Pueppke [24] found that nodule development induced by $E$. fredii is highly affected by the environment. Furthermore, Buendía Claveria et al. [21] and Yang et al. [23] found that inoculation of soybeans with $E$. fredii in alkaline soils in Spain and China resulted in a higher number of nitrogen fixing nodules compared to $B$. japonicum inoculated plants. Furthermore, Videira et al. [22] found a strong genotype-rhizobia interaction and Yang et al. [25] demonstrated that plant $\mathrm{R}$ genes are also involved in the interaction. Considering this, the success of rhizobia to develop nodules on soybean might be dependent on the ability of the isolates to compete for infection sites, on their ability to evade the plant's autoregulatory mechanism and on the cultivar nodulation capacity and genotype.

Nodulation of soybean has been carefully studied and described by Calvert et al. [26]. Pierce and Bauer [27] and Takats [28] described an autoregulatory mechanism in soybean that arrests infections, whether plants were inoculated with fast or slow growing rhizobia $[29,30]$. However, it has been observed that under defined environmental conditions fast growing rhizobia developed more nodules than $B$. japonicum inoculated plants (Balatti, P., personal communication, Universidad Nacional de La Plata, 2012). This raised the question, is the higher number of infections a result of the ability of fast growers to avoid the plant's mechanism of autoregulation? Therefore, the purpose of this work was to study the number of infections and nodulation of soybean roots inoculated either with $B$. japonicum or $E$. fredii, what might lead us to see if any of these bacteria can avoid the plant autoregulatory mechanism. Also, we evaluated the effect of the soybean cultivar and soil $\mathrm{pH}$ on the competitive ability of E. fredii and B. japonicum. 


\section{MATERIALS AND METHODS}

\subsection{Growth and Numbers of Bacterial Strains Used}

Stocks and cultures of the strains used in this study were done as described by Chatterjee et al. [31]. Bacteria were grown in yeast extract mannitol (YEM) medium [32] in an orbital shaker at $150 \mathrm{rpm}$ at $28^{\circ} \mathrm{C}$. E. fredii $\mathrm{SMH} 12$ [33] and S40 [34]) were kindly provided by Dr. J E. Ruiz Sainz, (Universidad de Sevilla) Seville, Spain. $B$. japonicum E109 (a derivative of USDA138) is a commercial strain used in Argentina. Mutant $E$. fredii S40-1 is Streptomycin (Str) resistant mutant (Martinez Alcántara, this work).

Bacterial cell concentration was adjusted by means of the Optical Density (O.D.) at $625 \mathrm{~nm}$ in a spectrophotometer Shimadzu UV160A [32].

\subsection{Plant Growth Conditions}

Seeds of soybean (Glycine max (L.) Merr.) cv Asgrow 4400 RG were surface sterilized [31], and were germinated in plates containing $1 \%$ water agar, which were incutabed at $28^{\circ} \mathrm{C}$ for two days. Then, seedlings were transplanted to modified Leonard Jars, filled with a mixture of 2 parts of vermiculite and one part of soil (sieved horizon A) [30]. The soil used in the experiments contained $23 \mathrm{ppm}$ of $\mathrm{P}, 53 \mathrm{ppm}$ of $\mathrm{NO}_{3}$, and $3.3 \%$ of organic matter. Plants were grown in the greenhouse under a $16 \mathrm{~h}$ photoperiod at $27^{\circ} \mathrm{C} \pm 2$ and $20 \pm 2^{\circ} \mathrm{C}$ during the night. Samples were taken 5 and 30 days after inoculation and roots were screened for the presence of nodules. Shoot dry weight was determined by drying the shoots in an oven at $60^{\circ} \mathrm{C}$ until constant weight.

\subsection{Infection Initiation in Roots}

Seeds were inoculated by immersing plantlets roots in bacterial suspensions of a) $10^{3}$; b) $10^{4}$; c) $10^{5}$; d) $10^{6}$; e) $10^{7}$; and f) $10^{8}$ cell. $\mathrm{ml}^{-1}$. Plants were harvested five days after inoculation and the roots were stained by the Haematoxylin method [35]. The number of initiation sites was counted by means of a stereoscope Leitz SM Lux microscope. A replicate included 4 plants and the number of replicates per experiments was 6 (total number of plants assayed were 24). Three independent experiments were run. The experimental design was completely at random and the statistical analysis performed was the ANOVA (Statgraphics software). Means were compared by the Least Significant Difference (LSD). A remaining subset of plants (24) was cultivated in the greenhouse for 25 additional days, then 30 days old plants were harvested and the nodules were counted.

\subsection{Competitive Ability of the Strain}

We performed a different set of experiments to evaluate the competitive ability of two strains, $E$. fredii $\mathrm{SMH} 12$, a highly efficient nitrogen fixing bacteria, $\mathrm{S} 40$ an isolate pretty much diverse from SMH12 (molecular data) and B. japonicum E109 (the commercial strain used in inoculants in Argentina) to infect and colonize soybean roots, which was analyzed by identifying the rhizobia occupying the nodules of soybean grown in Leonard jars, as described before. We also studied the effect of the soil $\mathrm{pH}$ and plant genotype on competition. Three independent experiments were performed each included the following treatments: A) uninoculated plants; B) Plants inoculated with $10^{8}$ cells of $B$. japonicum; C) Plants inoculated with $10^{8}$ cells of E. fredii, D) Plants inoculated with a mixture of $B$. japonicum and $E$. fredii cells in a 2:1 ratio; E) Plants inoculated with a mixture of $B$. japonicum and $E$. fredii cells in a 1:1 ratio F) Plants inoculated with a mixture of $B$. japonicum and $E$. fredii cells in a $1: 2$ ratio. In the first experiment we evaluated the competitive ability of $E$. fredii strain $S 40$ while in the second one that of strain $E$. fredii $\mathrm{SMH} 12$, both of them on soybean cultivar Asgrow 4400. In the third experiment, we evaluated the effect of the soybean cultivar on the competitive ability of $\mathrm{SMH} 12$ repeating the competitive experiments on three different soybean cultivars NA2018GR, NA4990GR and A7053GR. In addition to this, we also evaluated the effect of $\mathrm{pH}$ upon the competitive ability of SMH12 by growing cultivar NA4990GR in media buffered at two different pHs, 7 and 8. Plants were seeded and inoculated with a 2:1, 1:1 and 1:2 E. fredii / B. japonicum ratio. In this experiment, bacteria were inoculated by adding them to the soil substratum, before the seedlings were transplanted. Thirty days after inoculation nodules were collected, counted and surface sterilized by immersing in $50 \%$ ethyl alcohol for $5 \mathrm{~min}$ and in $50 \%$ sodium hypochlorite for $5 \mathrm{~min}$. Then, they were rinsed with sterile distilled water and rounded in circles on media to check for the presence of contaminants on their outside. The experiments were performed in a randomized block design with three replicates and a one way ANOVA statistical test $(P \leq 0.05)$ was run by means of the Statgraphics software. 


\subsection{Identification of Soil and Nodule Bacteria}

Each nodule was crushed in $20 \mu$ sterile water and two drops of the homogenate were plated on TY [36] or YEM containing $2 \mathrm{~g}$ of yeast extract, supplemented with the required antibiotics: Streptomycin (Str), (400 $\left.\mu \mathrm{g} \cdot \mathrm{ml}^{-1}\right), \quad$ and Tetracycline (Tet), $\left(5 \mu \mathrm{g} \cdot \mathrm{ml}^{-1}\right)$. While E. fredii S40 and SMH12, grew on TY and YEM media, $B$. japonicum E109 grew on YEM in the presence of Tet and did not grow on TY media. The identity of the bacteria recovered either from the nodules or the soil was confirmed by means of the amplification of a 900 bp or 750 bp bands that correspond to $B$. japonicum and $E$. fredii, respectively [37]. Briefly, the soil DNA was extracted based on a modified procedure described by Volossiuk et al. [38]. Loops picked up from the colonies were used as templates for the Multiplex PCR.

\section{RESULTS AND DISCUSSION}

Both experiments where soybeans were inoculated with increasing cell numbers of $E$. fredii or $B$. japonicum generated identical results, therefore only one of them is presented (Figs. 1A-D). The number of infections sites were independent of the number of rhizobia inoculated $\left(R^{2}=0.012\right)$ (Figs. $1 A$ and $\left.1 B\right)$. B. japonicum and $E$. fredii were equally effective at inducing infections. A subset of plants cultured for 25 additional days developed nodules and their number was a function of the rhizobium cell concentration (Figs. 1C and 1D). However, nodule number was much lower than the number of infections observed 5 days after inoculation suggesting that as has been described by Calvert et al. [26] infections might have been arrested. However, E. fredii inoculated plants developed a higher number of nodules (17 nodules) than $B$. japonicum inoculated ones (11 nodules). Furthermore, the number of $E$. fredii cells required by soybeans to nodulate was lower than with Bradyrhizobium. This basically suggests that at least fast growing rhizobia seem to be more effective in evading autoregulation.

On a per plant basis or expressed as nitrogenase specific activity, the plants had similar levels of fixation, whether they were inoculated with fast or slow growing rhizobia (data not shown), another argument about the inefficiency of fast growing rhizobia.

As another index of efficiency, we analyzed the number of nodules developed by $E$. fredii and/or
$B$. japonicum when soybeans were coinoculated in a $2: 1,1: 1$ and $1: 2$ ratios of rhizobia, which was confirmed by a Multiplex PCR reaction [37] (Fig. 2). B. japonicum seemed to be a better competitor than $E$. fredii, considering that independently of the ratio of cells inoculated, whenever they were coinoculated, most nodules contained $B$. japonicum, whether the $E$. fredii strain coinoculated was SMH12 or S40 (Table 1) (Fig. 2). When the assays were performed with E. fredii strain S40, coinoculation with a 2:1, 1:1 or 1:2 B. japonicum / E. fredii S40 ratio, 91.9, 78.2 and $92.2 \%$ of the nodules contained $B$. japonicum, respectively and the rest either $E$. fredii alone or both $B$. japonicum and $E$. fredii (Fig. 3).

We evaluated further the effect of the plant genotype and soil $\mathrm{pH}$ upon the competitive ability of $E$. fredii and $B$. japonicum and found that whether the soybean cultivar belonged to the short, middle or late maturity group, nodules contained mostly bradyrhizobia (Fig. 3). In addition to this, we found that $B$. japonicum consistently formed more nodules than $E$. fredii (Fig. 3), which tended to decrease at pH8 (data not shown). This is in a way in agreement with the findings reported by Zhang et al. [39]; these authors stated that rhizobia distribution in the soils of China was a function of the soil $\mathrm{pH}$ and also the availability of nutrients such as N, P and $\mathrm{K}$. This was such that they demonstrated biogeographic clustering of rhizobia, since the major soybean producing areas of North China Plain, together with a subtropical region in China and alkaline soils in India have a unique composition of rhizobia that were mostly fast growers.

Our results showed that both fast and slow growing bacteria developed a high number of infections in soybean, suggesting that both species were equally efficient in doing so, which was independent of the number of rhizobial cells inoculated. Heron and Pueppke [29] found that the slow growing strain 3 G4B16 had an infection/nodulation ratio 39 times greater than fast growing strain USDA191. However, while these authors looked at infection threads in a defined portion of the root, we looked at nodule initiation sites along the whole root and by means of a different staining technique.

Fast growing rhizobia were more efficient than $B$. japonicum at inducing nodulation and two lines of evidences support this. One is that fast growing rhizobia induce the same number of nodules with 
three order of magnitude less bacterial cells than B. japonicum (Figs. 1A y 1B), which might be related to a quorum sensing response along the establishment of a successful symbiosis [40]. These mechanisms seem to be mediating early to intermediate stages signaling events and probably in the case of $E$. fredii, quorum sensing influenced the events that occurred later in nodule development. The other line of evidence is that plants inoculated with $E$. fredii developed a higher number of nodules than with Bradyrhizobium, which was also reported by Heron and Pueppke [41] and Buendía Clavería et al. [21]. However, the number of infections developed 5 days after inoculation and the number of nodules were unrelated, which suggest that the autoregulatory mechanisms of the plant prevented nodule development [28]. Therefore, $E$. fredii was more effective than $B$. japonicum in infecting and nodulating soybean suggesting that infection foci induced by fast growers, somehow were less prone to the autoregulatory mechanism of soybean, at least with the cultivars assayed in these experiments.

Still, compared to B. japonicum, E. fredii had a low competitive ability. Whenever soybeans were coinoculated while most nodules were occupied only by $B$. japonicum, some contained both fast and slow growing rhizobia suggesting either that they shared the port of entry or complemented each other to successfully infect the plant, without affecting their viability. McLoughlin et al. [42] found that the nodules of soybeans inoculated with fast growing rhizobia and grown in soils containing native Bradyrhizobium contained almost exclusively bradyrhizobia. Manjanatha et al. [43] and de O. Chueire and Hungria [44] found that Bradyrhizobium strains outcompeted fast growing ones. These findings and ours allowed us to conclude that under the conditions described, basically neutral $\mathrm{pH}$, fast growing strains are competitive deficient. Under natural conditions if soybean plants are nodulated mostly by bradyrhizobia, their cell number in soils will increase and will lead to their prevalence in the soil.

Our findings confirmed that $B$. japonicum was more efficient than $E$. fredii to nodulate soybean cultivars whether they belong to short or long life cycle groups. Regarding this, it should be pointed out that the cultivars assayed in these experiments were all closely related with improved American cultivars; therefore they might have low specificity for $E$. fredii. Yang et al.
[23] found that the subpopulations of rhizobia in the soils of China showed strong cultivar specificity; therefore the competitive ability of fast and slow growing rhizobia might be a function of the soybean genotype genome. Still $\mathrm{Han}$ et al. [45] stated that the soil environment is critical for the prevalence of fast growing rhizobia such as $\mathrm{pH}$ and $\mathrm{P}$ availability.

The $\mathrm{pH}$ of the media often influences the rhizobia-plant interaction. Li et al. [8] and Zhang et al. [39] described that E. fredii is highly affected by the soil environmental conditions, such as $\mathrm{pH}$ and available $\mathrm{P}[5 ; 45]$. In our experiments, the $\mathrm{pH}$ of the media did not subvert the fitness of $B$. japonicum and $E$. fredii, to nodulate improved soybean cultivars, since even at high $\mathrm{pH} B$. japonicum was the strain that occupied the highest percentage of nodules. However, it should be mentioned that as the $\mathrm{pH}$ of the media increased, a reduction in the number of nodules containing $B$. japonicum occurred even though no statistically significant difference was found (data not shown). Furthermore, at high $\mathrm{pH}$ we failed to isolate rhizobia from a considerable number of nodules, that PCR demonstrated had B. japonicum. Also in field experiments were soybeans coinoculated with fast and slow growing rhizobia presented empty nodules (PhD Balatti, P., personal communication, Universidad Nacional de La Plata, 2012). No bacteria were recovered from these surface sterilized nodules on YEM but the Multiplex PCR lead to the amplification of the 950 bp Bradyrhizobium specific fragment, suggesting that these nodules contained extremely low numbers of $B$. japonicum, which might be difficult to detect, unless a highly sensitive technique is used such as PCR. So even though the $\mathrm{pH}$ affected Bradyrhizobium it did not subvert the genomic determinants that made $B$. japonicum more competitive than E. fredii.

Our results showed that fast and slow growing rhizobia were equally efficient at developing the early events of nodulation as well as fixing atmospheric nitrogen in soybean. However, it appears that fast growing rhizobia nodulation events evaded the autoregulatory mechanisms of nodulation in plants more efficiently than those provoked by bradyrhizobia. Although the plant genome plays a critical role in the symbiosis it was unrelated to the competitive ability of rhizobia. Under the conditions described the soil $\mathrm{pH}$ had no effect on the competitive ability of both partners. 

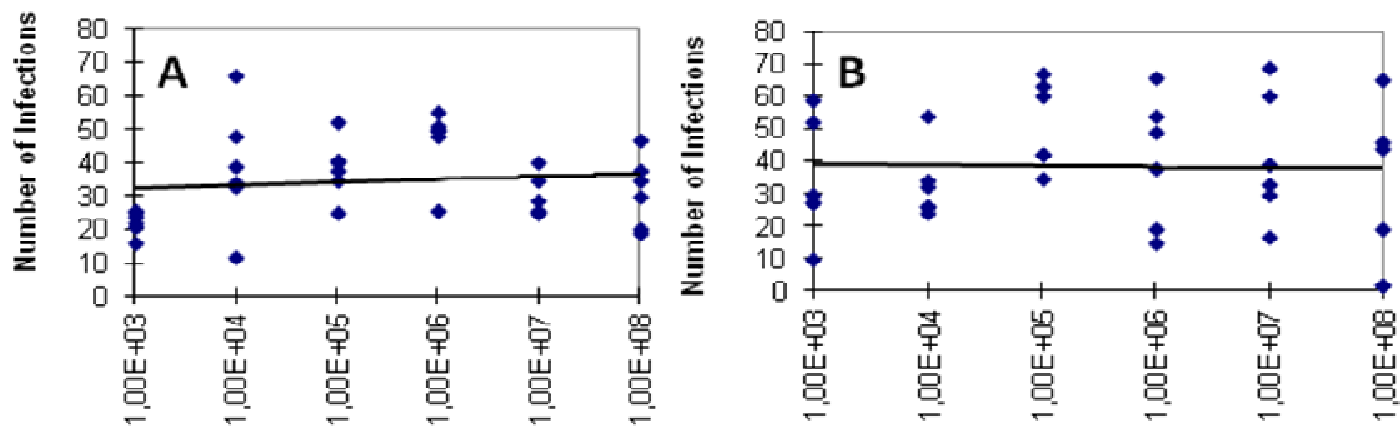

$$
\begin{aligned}
y= & 0,3474 \operatorname{Ln}(x)+30,21 \\
& R^{2}=0,0122, p: n s
\end{aligned}
$$$$
y=-0,0972 \operatorname{Ln}(x)+39,48
$$$$
\mathrm{R}^{2}=0,0004, p: \mathrm{ns}
$$
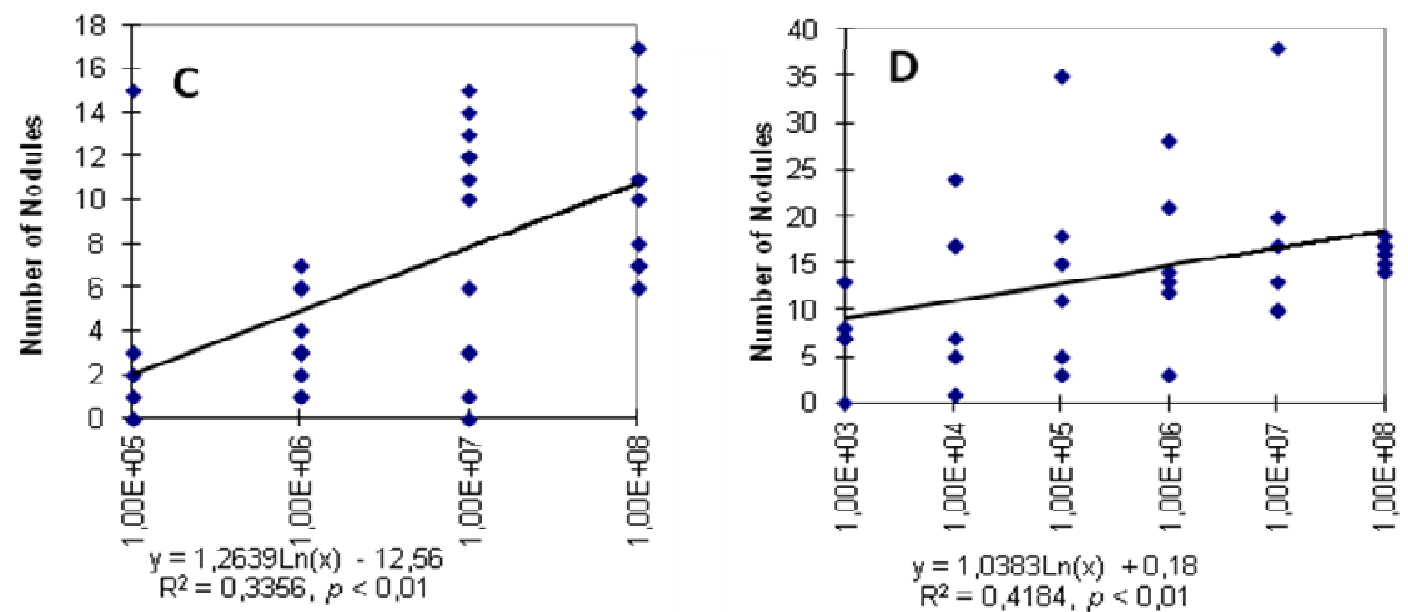

Fig. 1. Development of initiation sites and nodulation in roots of soybean plants inoculated with fast and slow growing rhizobia

Treatments were as follows a) $10^{3}$; b) $10^{4}$; c) $10^{5}$; d) $10^{6}$; e) $10^{7}$; f) $10^{8}$ bacterial cells. $\mathrm{m}^{1}$ of culture. A) Number of initiation sites developed by $B$. japonicum on soybean. B) Number of initiation sites developed by $E$. fredii on soybean. C) Number of nodules found on soybean plants inoculated with B. japonicum. D) Number of nodules found on soybean plants inoculated with $E$. fredii. Plants were inoculated and five days after infection, sites were counted as described. $n s=$ non significant at $P<0.05$

Table 1. Competitive ability of E. fredii strain SMH12 and B. japonicum E109 on soybean cultivar A4400GR in a 1:2 mixture of soil: vermiculite, respectively

\begin{tabular}{|c|c|c|c|c|c|}
\hline \multirow[t]{2}{*}{ Strains recovered } & \multicolumn{3}{|c|}{$\%$ Nodule occupancy } & \multirow{2}{*}{$\begin{array}{l}\text { Nodules } \\
\text { evaluated }\end{array}$} & \multirow{2}{*}{$\begin{array}{l}\% \text { of evaluated } \\
\text { nodules among total }\end{array}$} \\
\hline & B. japonicum & E. fredii & B.j. + E.f. & & \\
\hline Uninoculated control & - & - & - & - & - \\
\hline B. japonicum & $100 \mathrm{a}$ & 0 & 0 & 16 & 14 \\
\hline B.j. $2: 1$ E.f. & $100 \mathrm{a}$ & 0 & 0 & 30 & 20 \\
\hline B.j. 1:1 E.f. & $100 \mathrm{a}$ & 0 & 0 & 26 & 20 \\
\hline B.j 1:2 E.f & $100 \mathrm{a}$ & 0 & 0 & 26 & 20 \\
\hline E. fredii & $\mathrm{Ob}$ & 100 & 0 & 16 & 43 \\
\hline
\end{tabular}

The $\mathrm{pH}$ of the soil was 7.0. Nodules were collected from plants grown in modified Leonard jars containing each three plants. Bacteria were added to the soil substratum each at a concentration of $10^{8}$ bacteria. $g^{-1}$ of soil. The number of replicates was 15 plants 


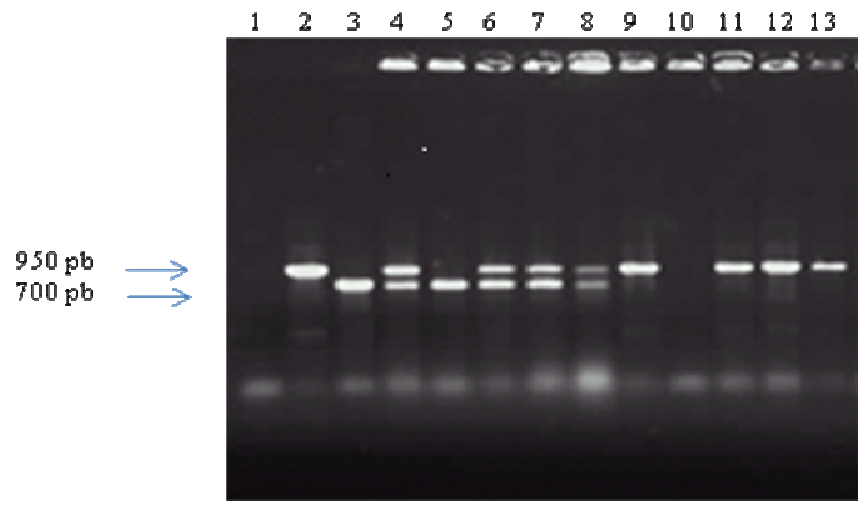

Fig. 2. $R S \alpha$ and nolB fragment amplification by means of the Multiplex PCR reaction performed with template DNA isolated from surface sterilized nodules

$R S \alpha$ is a $950 \mathrm{pb}$ fragment that is specific of Bradyrhizobium japonicum and nolB is a $700 \mathrm{pb}$ fragment specific of

Ensifer fredii. Lanes 1 control reaction lacking template DNA; lane 2: B. japonicum template DNA; lane 3: corresponds to template DNA of E. fredii (S40); lanes 4-13: correspond each lane to the amplifications performed using template DNA from nodules extracts, lanes 4-7: corresponds from 1:2 (B.j.: E.f.) treatment; lanes 8-10 from 1:1 (B.j.: E.f.) treatment; lanes 11-13: from 2:1 (B.j.: E.f.) treatment. This is a 1\% agarose gel run at 80 volts in TBE buffer

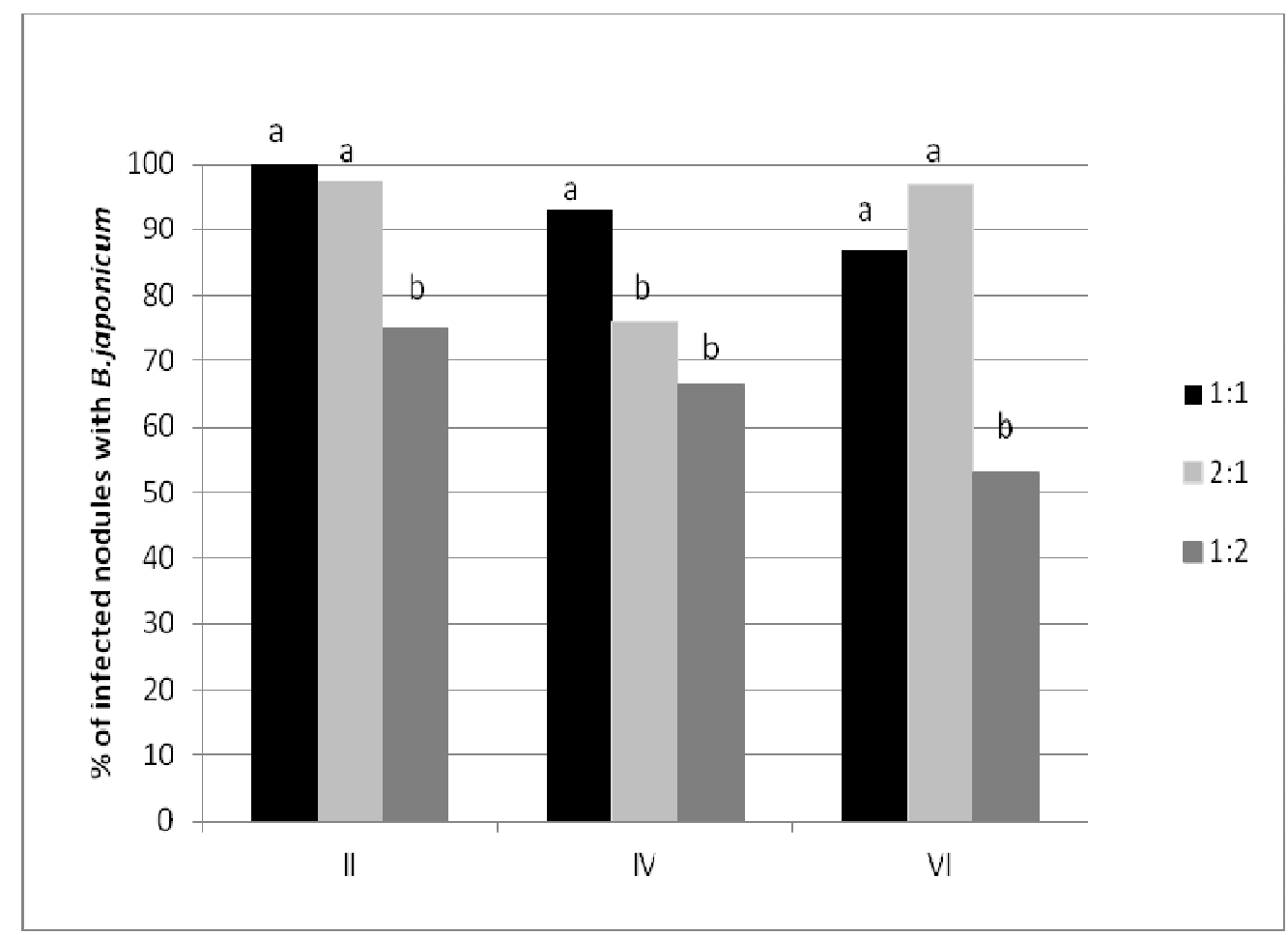

Fig. 3. Competitive ability of E. fredii SMH12 and B. japonicum E109 strains on soybean cultivar A4440GR cultivated in modified Leonard Jars

Percentage of nodules occupied either by fast and/or slow growing rhizobia in soils inoculated with different ratios of $B$. japonicum and $E$. fredii. Statistical differences are indicated by different letters $(P<0.05)$. At the base of the figure roman numbers indicate the maturity group of the soybean genotype used in the experiments. On the right numbers indicate the ratio of $B$. japonicum to $E$. fredii cells inoculated. The number of nodules evaluated for each inoculation treatment was: 485 for B. japonicum (not included in the figure); 485 for 2:1. (B.j.: E.f.); 432 for 1:1

(B.j.: E.f.); 438 for 1:2 (B.j.: E.f.); 497 for E. fredii (not included in the figure) 


\section{CONCLUSION}

E. fredii was as efficient as $B$. japonicum at inducing infection initiation sites on soybean roots, however $E$. fredii developed more nodules suggesting that less infections are within the control of the autoregulatory mechanism of soybean. Bradyrhizobium proved to be more competitive than $E$. fredii though this might be alterd by the soybean genotype and the soil environment. If at seeding we modify the seed environment, we might enhance nodulation by fast growing strains, which should rise their number in the soil. So there is a potential to formulate inoculants with fast growing rhizobia though to do this the genetic base of soybean cultivars might be broaden.

\section{COMPETING INTERESTS}

Authors have declared that no competing interests exist.

\section{REFERENCES}

1. Polhill RM, Raven PH, (eds). Advances in Legume Systematics. Part 1, The Royal Botanic Gardens, Kew; 1981.

2. Doyle JJ. Phylogeny of the legume family: An approach to understanding the origin of nodulation. Annu Ver Ecol Syst. 1994;25:325-349.

3. Long SR, Staskawicz BJ. Prokaryotic plant parasites. Cell. 1993;73:921-935.

4. Jarvis BDW, Van Berkum $P$, Chen WX, Nour SM, Fernandez MP, Cleyet-Marel JC, Gillis M. Transfer of Rhizobium loti, Rhizobium huakuii, Rhizobium ciceri, Rhizobium mediterraneum, and Rhizobium tianshanense to Mesorhizobium gen. nov. Int J Syst Bacteriol. 1997;47:895-898.

5. Camacho M, Santamaría C, Temprano F, et al. Soils of the Chinese Hubei province show a very high diversity of Sinorhizobium fredii strains. Syst. Appl. Microbiol. 2002;25:592-602.

6. Kuykendall DL, Genus I. Bradyrhizobium Jordan 1982, 137 vp. In: Brenner, D.J., Krieg NR, Staley JT, Garrity GM, (eds.). Bergey's Manual of Systematic Bacteriology. 2nd ed. Vol 2. New York (NY): Springer. 2005;438-443.

7. Balkwill DL, Genus VI. Ensifer Casida 1982, 343vp.In: Brenner DJ, Krieg NR, Staley JT, Garrity GM, (eds.). Bergey's Manual of Systematic Bacteriology. 2nd ed. New York (NY): Springer. 2005;2:356358.

8. Li, QQ, Wang ET, Zhang YZ, Zhang YM, Tian CF, Sui XH, Chen WF, Chen WX. Diversity and biogeography of Rhizobia isolated from root nodules of Glycine max grown in Hebei Province. China Microb Ecol. 2011;61:917-931.

9. Jordan DC. Transfer of Rhizobium japonicum Buchanan 1980 to Bradyrhizobium gen. nov., a genus of slow-growing, root nodule bacteria from leguminous plants. Int J Syst Bacteriol. 1982;32:136-139.

10. Kuykendall LD, Saxena B, Devine TE, Udell SE. Genetic diversity in Bradyrhizobium japonicum and a proposal for Bradyrhizobium elkanii sp. nov. Can J Microbiol. 1992;38:501-505.

11. $\mathrm{Xu}$ LM, Ge C, Cui Z, Li J, Fan H. Bradyrhizobium liaoningense sp. nov., isolated from the root nodules of soybeans. International J Syst Bacteriol. 1995;45:706711.

12. Wang JY, Wang $R$, Zhang $Y M$, Liu HC, Chen WF, Wang ET, Sui XH, Chen WX. Bradyrhizobium daqingense sp. nov., isolated from soybean nodules International. J Syst Evol Microbiol. 2013;63:616-624.

13. Trinick MJ. Relationships amongst the fastgrowing rhizobia Lablad purpureus, Leucaena leucocephala, Mimosa spp., Acacia farnesiana and Sesbania grandiflora and their affinities with other rhizobial groups. J Appl Bacteriol. 1980;49:39-53.

14. Keyser HH, Bohlool BB, Hu TS, Weber DF. Fast-growing rhizobia isolated from root nodules of soybean. Science. 1982;215:1631-1632.

15. Chen WX, Yan GH, Li JL. Numerical taxonomic study of fast-growing soybean rhizobia and a proposal that Rhizobium fredii be assigned to Sinorhizobium gen. nov. Int J Syst Bacteriol. 1988;38:392-397.

16. Peng GX, Tan ZY, Wang ET, ReinholdHurek B, Chen WF, Chen WX. Identification of isolates from soybean nodules in Xinjiang Region as Sinorhizobium xinjiangense and genetic differentiation of $S$. xinjiangense from Sinorhizobium fredii. Int $J$ Syst Evol. 2002;52:457-462.

17. Saldaña $G$, Martinez Alcántara V, Vinardel JM, Bellogín R, Ruiz Sainz JE, Balatti PA. Genetic diversity of fast growing rhizobia 
that nodulate soybean (Glycine max (L.) Merr). Arch Microbiol. 2003;180:45-52.

18. Hungria $M$, De O.Chueire L, Megias $M$, et al. Genetic diversity of indigenous tropical fast-growing rhizobia isolated from soybean nodules. Plant Soil. 2006;288:343-356.

19. Appunu C, Zoue AN, Laguerre L. Genetic diversity of native bradyrhizobia isolated from soybeans (Glycine max L.) In different agricultural-ecological- climatic regions of India. Appl Environ Microbiol. 2008;74:5991-5996.

20. Mak C, Tan EL, Lim ST, Azmi M. Infectivity and competitive ability of fast and slow growing Rhizobium strains on soybeans. Pertanika. 1990;13:151-157.

21. Buendia Claveria AAM, Rodriguez Navarro DN, Santamaría Linaza C, Ruiz Sainz JE, Temprano Vera F. Evaluation of the symbiotic properties of Rhizobium fredii European soils. Syst Appl Microbiol. 1994;17:155-160.

22. Videira LB, Pastorino GN, Balatti PA. Incompatibility may not be the rule in the Sinorhizobium fredii-soybean interaction. Soil Biol. Biochem. 2001;33:837-840.

23. Yang SS, Bellogín RA, Buendía A, Camacho M, Chen M, et al. Effect of pH and soybean cultivars on the quantitative analyses of soybean rhizobia populations. J Biotech. 2001;91:243-255.

24. Pueppke SG. Nodule distribution on legume roots: Specificity and response to the presence of soil. Soil Biol Biochem. 1986;18:601-606.

25. Yang S, Tang F, Gaoa M, Krishnan HB, Zhua H. R gene-controlled host specificity in the legume-rhizobia symbiosis. Proc Natl Acad of Science. 2010;107:187351874.

26. Calvert HE, Pence MK, Pierce M, Malik NSA, Bauer WD. Anatomical analysis of the development and distribution of Rhizobium infections in soybean roots. Can J Bot. 1984;62:2375-2384.

27. Pierce M, Bauer WD. A rapid regulatory response governing nodulation in soybean. Plant Physiology. 1983;73:286-290.

28. Takats ST. Early autoregulation of symbiotic root nodulation in soybeans. Plant Physiol. 1990;94:865-869.

29. Heron DS, Pueppke SG. Mode of infection, nodulation specificity and indigenous plasmids of 11 fast-growing Rhizobium japonicum strains. J Bacteriol. 1984;160:1061-1066.
30. Balatti PA, Pueppke SG. Identification of North American soybean lines that form nitrogen fixing nodules with Rhizobium fredii USDA257. Can J Plant Sci. 1992;72:49-55.

31. Chatterjee A, Balatti PA, Gibbons W, Pueppke SG. Interaction of Rhizobium fredii USDA257 and Nodulation Mutants derived from it with the agronomically improved soybean cultivar McCall. Planta. 1990;180:303-311.

32. Vincent JM. A manual for the practical study of Root Nodule Bacteria. Blackwell Scientific Publications, Oxford; 1970.

33. Cleyet-Marel JC. These dÉtat. University Claude Bernard-Lyon, Lyon, France; 1987.

34. Thomas-Oates J, Bereszczak J, Edwards E, Gill A. et al. A catalogue of molecular, physiological and symbiotic properties of soybean-nodulating rhizobial strains from different soybean cropping areas of China. Syst Appl Microbiol. 2003;26:453-465.

35. Green LS, Emerich DW. Light microscopy of early stages in the symbiosis of soybean with a delayed-nodulation mutant of Bradyrhizobium japonicum. J Exp Bot. 1999;50:1577-1585.

36. Beringer JE. R-factor transfer in Rhizobium leguminosarum. J Gen Microbiol. 1974;84:188-198.

37. Pastorino GN, Martinez Alcántara V, Balatti PA. Identification of fast and slow growing rhizobia nodulating soybean (Glycine max (L.) Merr.) by a multiplex PCR reaction. FEMS Microbiol Lett. 2003;229:153-158.

38. Volossiouk T, Robb EJ, Nazar RN. Direct DNA extraction for PCR-mediated assays of soil organisms. Appl Environ Microbiol. 1995;61:3972-3976.

39. Zhang YM, Li YJr, Feng Chen W, Wang ET, Tian CF, Li QQ, Yun ZZ, Xin HS, Chen WX. Biodiversity and biogeography of rhizobia associated with soybean plants grown in the North China Plain. Appl Environ Microbiol. 2011;77:6331-6342.

40. González JE, Marketon MM. Quorum sensing in nitrogen-fixing rhizobia. Microbiol Mol Biol Rev. 2003;67:574-592.

41. Heron DS, Pueppke SG. Regulation of nodulation in the soybean- Rhizobium symbiosis. Strain and cultivar varibility. Plant Physiol. 1987;84:1391-1396.

42. McLoughlin JT, Alt SG, Owens PA, Fetherston C. Competition for nodulation of field grown soybeans by strains of 
Rhizobium fredii. Can J Microbiol. 1986;32:183-186.

43. Manjanatha MG, Loynachan TE, Aterly GA. Efficiency, competitiveness and persistency of Chinese Rhizobium fredii in lowa soils. Agron J. 1992;84:676-681.

44. De O, Chueire LM, Hungría M. $\mathrm{N}_{2}$-fixation ability of Brazilian soybean cultivars with
Sinorhizobium fredii and Sinorhizobium xingiangensis. Plant and Soil. 1997;196:15.

45. Han LL, Wang ET, Han TX, et al. Unique community structure and biogeography of soybean rhizobia in the saline alkaline soils of Xinjiang, China. Plant Soil. 2009;324:291-305.

(c) 2015 Pastorino et al.; This is an Open Access article distributed under the terms of the Creative Commons Attribution License (http://creativecommons.org/licenses/by/4.0), which permits unrestricted use, distribution, and reproduction in any medium, provided the original work is properly cited.

Peer-review history:

The peer review history for this paper can be accessed here: http://www.sciencedomain.org/review-history.php?iid=682\&id=37\&aid=6346 